\title{
The Use of Electron Microscopy Techniques to Determine the Oxidation Mechanism SiAlON Ceramics Containing $\mathrm{Yb}_{2} \mathrm{O}_{3}+\mathrm{Sm}_{2} \mathrm{O}_{3}+\mathrm{CaO}$ as Sintering Additives
}

\author{
Sinem Baskut, Servet Turan
}

Faculty of Engineering and Architecture, Department of Materials Science and Engineering, Anadolu University, Eskisehir, Turkey

SiAlON ceramics are used in advanced technology areas including mechanic, chemistry, metallurgy, optic, automotive and defense industry which requires particularly high temperature resistance due to their excellent physical, chemical and mechanical properties. However, SiAlON ceramics are thermodynamically instable in an oxidizing environment due to the sintering additives used to improve densification, fracture toughness and hardness [1].

The aim of this study is to investigate the oxidation mechanism of " $\mathrm{Yb}_{2} \mathrm{O}_{3}+\mathrm{Sm}_{2} \mathrm{O}_{3}+\mathrm{CaO}$ " doped SiAlON ceramics at high temperatures by using microscopy techniques. For this purpose, samples were sintered in gas pressure sintering furnace. After sintering, the samples were polished and exposed to oxidation in high temperature furnace at $1400{ }^{\circ} \mathrm{C}$ for 72 hours. Then, the backscatter electron images, EDX analysis (Oxford Instruments, INCA ENERGY) and EBSD analysis (Oxford Instruments, INCA HKL) were taken at scanning electron microscope (Zeiss, SUPRA 50 VP) from both the surface and cross sections of oxidized samples without coating in variable pressure mode.

$\mathrm{XRD}$ result not given here indicated that $\mathrm{Yb}_{2} \mathrm{Si}_{2} \mathrm{O}_{7}$ (keivite) and crystoballite were formed at the surface of oxidized sample. Also, oxide layer formation was detected by the help of backscatter electron image which is given in Figure 1 (a). In the oxide layer newly formed rod like, light grey phase and dark grey phase was found as a mixture.

To examine the formation of the oxide layer and the microstructural modifications occur in the main material during the oxidation, the backscatter electron image was taken from cross section of the sample. As shown in the Figure 1 (e) three different regions formed in the main material during oxidation. The region A in main material is not affected by oxidation. Modifications occurred in region $\mathrm{B}$ by the help of diffusion of sintering additives through grain boundaries to the surface. Region $\mathrm{C}$ is the most affected zone from oxidation and includes silica layer which is located in the interface of SiAlON and oxide layer [2]. Backscatter cross section image (Figure 1 (c)) shows that rod like light grey crystals dispersed at the surface whereas black spherical shaped crystals located at oxide-nitride interface.

EDX analysis given in Figure 1 (f) were obtained from three different phases observed in the oxide layer. When EDX analysis were jointly evaluated with XRD results it can be deduced that rod like light grey crystals (1) are $\mathrm{Yb}_{2} \mathrm{Si}_{2} \mathrm{O}_{7}$, spherical like black crystals (2) are crystoballite and dark grey phase (3) is dopant rich glassy phase.

Crystal orientation maps obtained from the surface and cross section of oxidized sample are shown in Figure 1 (b) and (d). In the orientation maps $\mathrm{Yb}_{2} \mathrm{Si}_{2} \mathrm{O}_{7}$ crystals are distributed in black color glassy phase. Also, color differences in orientation maps showed that the $\mathrm{Yb}_{2} \mathrm{Si}_{2} \mathrm{O}_{7}$ crystals were not grown in one direction by controlled manner. 


\section{References:}

[1] J. Yu, H. Du, R. Shuba, I. Chen, 'Dopant-dependent oxidation behavior of $\alpha$-SiAlON ceramics', Journal of Material Science, 39 (2004), 4855-4860

[2] L.O. Nordberg, M. Nygren, P.O. Kall, Z. Shen, 'Stability and Oxidation Properties of RE- $\alpha$ SiAlON Ceramics (RE = Y, Nd, Sm, Yb)’, Journal of Material Science, 81 (1998) 1461-70
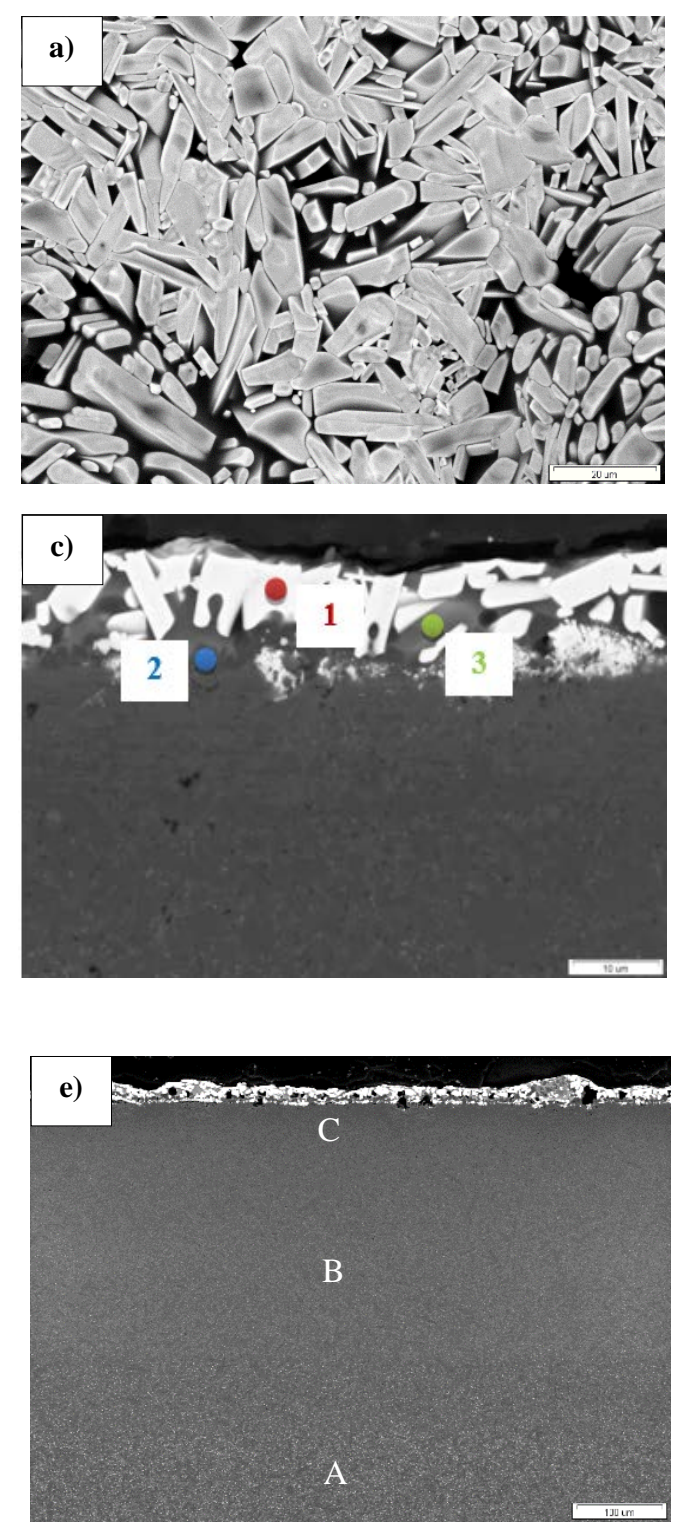
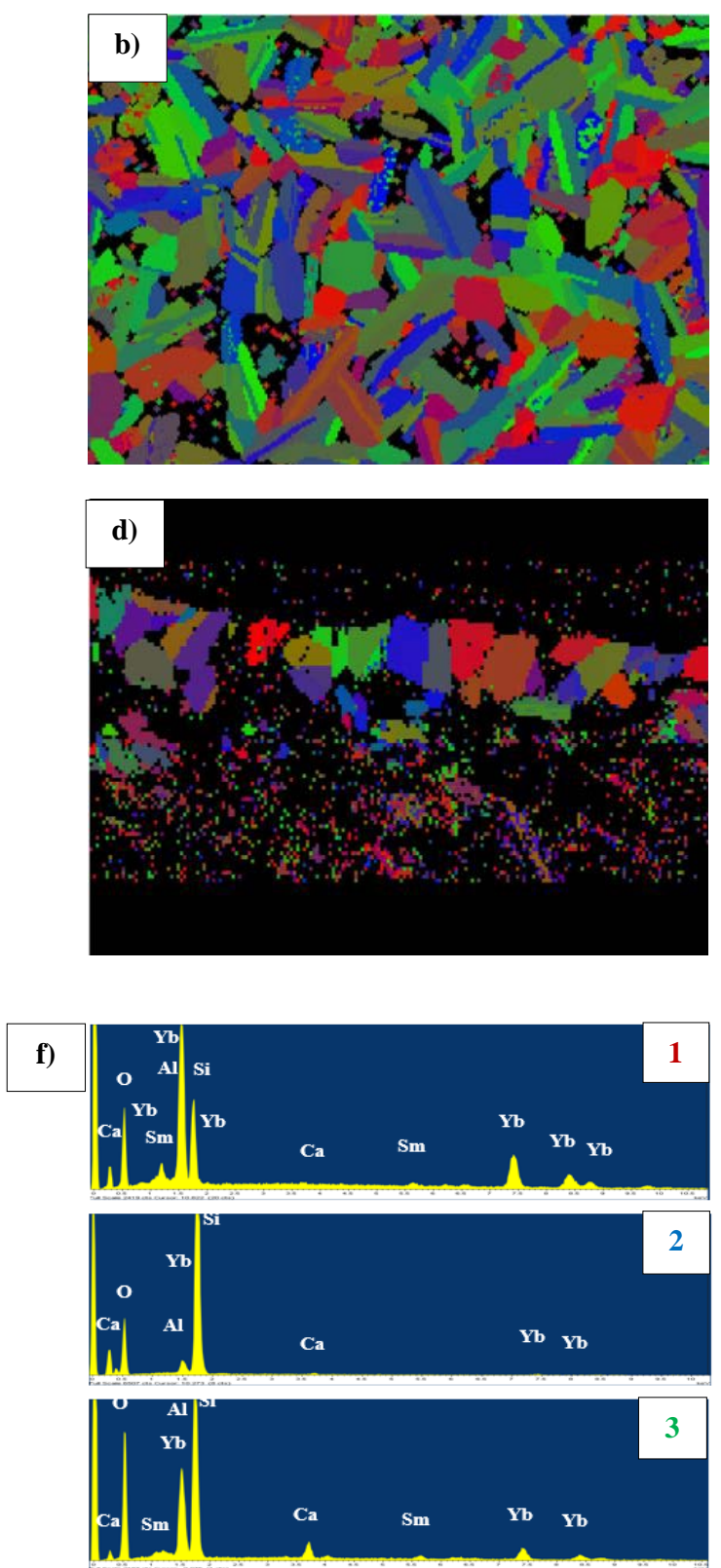

Figure 1. Back scattered images (a, c, e) and EBSD orientation maps (b, d) are given along with EDX analysis (f) from different regions on (e). 